\title{
United States Health Care System: A Pharmacy Perspective
}

\author{
David M Scott
}

\section{HEALTH CARE SYSTEMS AND FINANCING}

$\mathrm{T}$ he health care delivery system in the United States is described by some as the best in the world. For those who are uninsured or underinsured, however, it is described as the worst in the world.

In 1960, about $5 \%$ of the gross domestic product paid for health care services; in 2013, this proportion was estimated at $17.4 \% .{ }^{1}$ Given the amount of money that is spent each year, the United States should be doing much better on health indicators such as infant mortality rates and life expectancy. In this article, I will begin by describing national health expenditures in the United States and then go on to describe the country's health care system, including the public and private health care sectors and the pharmacy workforce, concluding with some thoughts on future directions.

As shown in Table 1, more than US\$2.9 trillion (US\$9255 per person) is spent annually in the United States on health care (data for 2013, the most recent year for which national health expenditures are available). ${ }^{1}$ Within the framework of President Lyndon B Johnson's "Great Society" era, the Medicare and Medicaid (public sector) programs were established in 1965 with the belief that health care is a "right" and not a "privilege". The Patient Protection and Affordable Care Act (known as the ACA or ObamaCare) of 2010 was proclaimed by some as a landmark in health care reform that would transform the US health care delivery system into a program that provides "health care as a right." Although the ACA does much to reduce major gaps in coverage for many Americans, it does not provide health care as a right. Passage of the ACA has created substantial public debate on what should be covered and who should pay.

Since the early 1900s, the United States has periodically considered the need for a nationalized health care program, but each time, this type of reform has been defeated. Instead of a single-payer system, the United States has a mix of public sector and private sector programs. The public sector programs include Medicare, Medicaid, health care delivery to underserved populations (through the Indian Health Service and
Community Health Centers), and other government-sponsored health care (in prisons, public clinics, and hospitals). The private sector includes most community hospitals, professional services (physician, dental, and other), nursing facilities, retail outlets selling medical products (e.g., prescription drugs, durable medical equipment), and health insurance companies (nonprofit organizations [e.g., Blue Cross and Blue Shield], commercial insurance companies [e.g., Aetna, Cigna, Prudential], and managed care providers [e.g., UnitedHealthcare, Humana]). Until recently, public health activities such as health prevention activities have been poorly funded (between $1 \%$ and $3 \%$ of national health expenditures), but in 2010 they received a significant boost with passage of the ACA. Overall, the largest spending category is for hospital care $(32.1 \%)$, followed by physician services $(20.1 \%)$, and prescription drugs $(9.3 \%)$ (Table 1). ${ }^{1}$

Table 2 summarizes national health expenditures by type of health insurance. About two-thirds (US\$2.1 trillion) of all expenses are paid by private health insurance, and the remainder of insurance is from the public sector (about US\$586 billion for Medicare and US $\$ 449$ billion for Medicaid). ${ }^{2}$ The complexity of US health care financing results in a situation where costs are massive for both the private sector and the public sector, representing a major concern for policy-makers, employers, and consumers. It might be expected that these high costs would result in the best health outcomes in the world; however, such is not the case. Although health care reform is often discussed, needed change is hampered by powerful lobbies (e.g., health insurance companies, pharmaceutical firms, health care systems). The lobbying groups, combined with Americans' fear of "big government" and "socialized medicine", tend to limit meaningful movement toward a single-payer system or another type of health care reform.

Health care costs are rising much faster than costs in other sectors of the economy, and a double-digit rate is expected to continue for some time. The US system prides itself on high-quality, high-technology health care, but such care is 
This single copy is for your personal, non-commercial use only.

For permission to reprint multiple copies or to order presentation-ready copies for distribution, contact CJHP at cjhpedit@cshp.ca

Table 1. National Health Expenditures for 1960-2013, by Aggregate Amount and Percent Distribution*

\begin{tabular}{|c|c|c|c|c|c|c|c|}
\hline Type of Expenditure & 1960 & 1970 & 1980 & 1990 & 2000 & 2010 & 2013 \\
\hline & \multicolumn{7}{|c|}{ Amount in US\$ Billions } \\
\hline Total health expenditures & 27.4 & 74.9 & 255.8 & 724.3 & 1378.0 & 2604.1 & 2919.1 \\
\hline Health consumption expenditures & 24.8 & 67.1 & 235.7 & 675.6 & 1290.0 & 2454.5 & 2754.5 \\
\hline Personal health care & 23.4 & 63.1 & 217.2 & 616.8 & 1165.7 & 2196.2 & 2468.6 \\
\hline Hospital care & 9.0 & 27.2 & 100.5 & 250.4 & 415.5 & 814.9 & 936.9 \\
\hline Professional services & 8.0 & 19.8 & 64.6 & 208.1 & 390.2 & 694.2 & 777.9 \\
\hline Physician and clinical services & 5.6 & 14.3 & 47.7 & 158.9 & 290.9 & 519.0 & 586.7 \\
\hline Other professional services & 0.4 & 0.7 & 3.5 & 17.4 & 37.0 & 69.8 & 80.2 \\
\hline Dental services & 2.0 & 4.7 & 13.4 & 31.7 & 62.3 & 105.4 & 111.0 \\
\hline Other health, residential, and personal care & 0.5 & 1.3 & 8.5 & 24.3 & 64.5 & 128.5 & 148.2 \\
\hline Home health care $\neq$ & 0.1 & 0.2 & 2.4 & 12.6 & 32.4 & 71.2 & 79.8 \\
\hline $\begin{array}{l}\text { Nursing facilities and continuing care } \\
\text { retirement communities } \neq \S\end{array}$ & 0.8 & 4.0 & 15.3 & 44.9 & 85.1 & 143.0 & 155.8 \\
\hline Retail outlet sales of medical products & 5.0 & 10.6 & 25.9 & 76.5 & 177.9 & 344.4 & 370.0 \\
\hline Prescription drugs & 2.7 & 5.5 & 12.0 & 40.3 & 121.2 & 256.2 & 271.1 \\
\hline Durable medical equipment & 0.7 & 1.7 & 4.1 & 13.8 & 25.2 & 37.0 & 43.0 \\
\hline Other nondurable medical products & 1.6 & 3.3 & 9.8 & 22.4 & 31.6 & 51.2 & 55.9 \\
\hline Government administration & 0.1 & 0.7 & 2.8 & 7.2 & 17.1 & 30.5 & 37.0 \\
\hline Net cost of health insurance ${ }^{* *}$ & 1.0 & 1.9 & 9.3 & 31.6 & 64.2 & 152.3 & 173.6 \\
\hline \multirow[t]{2}{*}{ Government public health activities } & 0.4 & 1.4 & 6.4 & 20.0 & 43.0 & 75.5 & 75.4 \\
\hline & \multicolumn{7}{|c|}{ \% Distribution } \\
\hline Total health expenditures & 100.0 & 100.0 & 100.0 & 100.0 & 100.0 & 100.0 & 100.0 \\
\hline Health consumption expenditures & 90.6 & 89.6 & 92.1 & 93.3 & 93.6 & 94.3 & 94.4 \\
\hline Personal health care & 85.4 & 84.3 & 84.9 & 85.2 & 84.6 & 84.3 & 84.6 \\
\hline Hospital care & 32.8 & 36.3 & 39.3 & 34.6 & 30.2 & 31.3 & 32.1 \\
\hline Professional services & 29.3 & 26.4 & 25.3 & 28.7 & 28.3 & 26.7 & 26.6 \\
\hline Physician and clinical services & 20.6 & 19.1 & 18.7 & 21.9 & 21.1 & 19.9 & 20.1 \\
\hline Other professional services & 1.4 & 1.0 & 1.4 & 2.4 & 2.7 & 2.7 & 2.7 \\
\hline Dental services & 7.3 & 6.3 & 5.2 & 4.4 & 4.5 & 4.0 & 3.8 \\
\hline Other health, residential, and personal caret & 1.6 & 1.8 & 3.3 & 3.4 & 4.7 & 4.9 & 5.1 \\
\hline Home health care $\neq$ & 0.2 & 0.3 & 0.9 & 1.7 & 2.4 & 2.7 & 2.7 \\
\hline $\begin{array}{l}\text { Nursing facilities and continuing care } \\
\text { retirement communities } ₫ \S\end{array}$ & 3.0 & 5.4 & 6.0 & 6.2 & 6.2 & 5.5 & 5.3 \\
\hline Retail outlet sales of medical products & 18.4 & 14.1 & 10.1 & 10.6 & 12.9 & 13.2 & 12.7 \\
\hline Prescription drugs & 9.8 & 7.3 & 4.7 & 5.6 & 8.8 & 9.8 & 9.3 \\
\hline Durable medical equipment & 2.7 & 2.3 & 1.6 & 1.9 & 1.8 & 1.4 & 1.5 \\
\hline Other nondurable medical products & 5.9 & 4.4 & 3.8 & 3.1 & 2.3 & 2.0 & 1.9 \\
\hline Government administration & 0.2 & 1.0 & 1.1 & 1.0 & 1.2 & 1.2 & 1.3 \\
\hline Net cost of health insurance ${ }^{* *}$ & 3.7 & 2.5 & 3.6 & 4.4 & 4.7 & 5.8 & 5.9 \\
\hline Government public health activities & 1.4 & 1.8 & 2.5 & 2.8 & 3.1 & 2.9 & 2.6 \\
\hline
\end{tabular}

*Source: US Department of Health and Human Services, Centers for Medicare and Medicaid Services, Office of the Actuary, National Health Statistics Group. ${ }^{1}$ Modified from Table 2, national health expenditures by health insurance for 2013 (national health expenditures by aggregate, annual percentage change, and per capita amounts by type).

tIncludes expenditures for residential care and medical care in nontraditional settings (i.e., community centres, senior centres, schools, military).

flncludes freestanding facilities.

§Includes care in nursing facilities, continuing care retirement communities, government nursing facilities (state, federal, local). IIncludes administrative costs (federal, state, local salaries) and insurance programs (Medicare, Medicaid, Children's Health Insurance Program, Defense, Veterans Affairs, Indian Health Service, workers' compensation, maternal and child health, etc.). **Net cost of health insurance is the difference between premiums and benefits paid for private health insurance.

expensive, and very few of the high-tech interventions have been clearly shown to be of benefit. Furthermore, individuals in the mainstream of US society do not want to pay for other people's health care. With recent congressional attempts to reduce funding for public sector programs (specifically the Medicare and Medicaid programs), the gap between "right" and "privilege" will undoubtedly become wider.

\section{PUBLIC HEALTH CARE SECTOR}

\section{Medicare}

Medicare beneficiaries are covered by the Social Security Amendment, passed in 1965 and then amended in 1972, which extended health care services to all persons 65 years of age or older. Medicare Part A covers inpatient hospital care, 
This single copy is for your personal, non-commercial use only.

For permission to reprint multiple copies or to order presentation-ready copies for distribution, contact CJHP at cjhpedit@cshp.ca

Table 2. Type and Source of National Health Expenditures for 2013*

\begin{tabular}{|c|c|c|c|c|c|c|c|c|c|}
\hline \multirow[b]{2}{*}{ Type of Expenditure } & \multirow[b]{2}{*}{ Total } & \multirow[b]{2}{*}{$\begin{array}{l}\text { Out of } \\
\text { Pocket }\end{array}$} & \multirow[b]{2}{*}{$\begin{array}{l}\text { Health } \\
\text { Insurance }\end{array}$} & \multicolumn{4}{|c|}{ Health Insurance } & \multirow[b]{2}{*}{$\begin{array}{l}\text { Other } \\
\text { Third- } \\
\text { Party } \\
\text { Payers }\end{array}$} & \multirow[b]{2}{*}{$\begin{array}{c}\text { Public } \\
\text { Health } \\
\text { Activity }\end{array}$} \\
\hline & & & & $\begin{array}{c}\text { Private } \\
\text { Health } \\
\text { Insurance }\end{array}$ & Medicare & Medicaid & $\begin{array}{c}\text { Other } \\
\text { Health } \\
\text { Insur. } \\
\text { Progr. }\end{array}$ & & \\
\hline & \multicolumn{9}{|c|}{ Amount in US\$ Billions } \\
\hline Total health expenditures for 2013 & 2919.1 & 339.4 & 2102.9 & 961.7 & 585.7 & 449.4 & 106.1 & 236.8 & 75.4 \\
\hline Health & D & & 9 & 96 & 585.7 & 449.4 & 106.1 & 236.8 & \\
\hline Personal health care & 2468.6 & 339.4 & 1907.9 & 846.0 & 550.5 & 410.8 & 100.6 & 221.2 & - \\
\hline Hosp & 936.9 & & 808.7 & 0 & 242.7 & 163.5 & 54.4 & 95.6 & - \\
\hline ervices & 9 & 12 & 1 & 5 & 148.8 & 62.6 & 27.1 & 66.8 & - \\
\hline inical services & 7 & & 4 & 2 & 130.3 & 50.1 & 24.1 & 59.2 & - \\
\hline 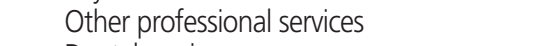 & 2 & $\angle$ & 6 & 29.3 & 18.0 & 5.0 & 0.3 & 7.0 & - \\
\hline & & & & 52.6 & 0.5 & 7.5 & 2.7 & 0.5 & - \\
\hline rsonal care§ & & & & & 5.1 & 82.6 & 4.5 & 41.8 & - \\
\hline Hom & & 6.4 & 70.9 & 6.3 & 34.4 & 29.1 & 1.1 & 2.4 & - \\
\hline $\begin{array}{l}\text { Nursing facilities and continuing care } \\
\text { retirement communities } \|^{* *}\end{array}$ & 155.8 & 45.8 & 98.5 & 12.6 & 34.6 & 46.9 & 4.5 & 11.5 & - \\
\hline products & 3 & 8 & 243.0 & 122.9 & 85.0 & 26.1 & 9.0 & 3.1 & - \\
\hline & 271.1 & & 222.7 & 117.9 & 74.6 & 21.2 & 8.9 & 2.5 & - \\
\hline Dur & 43.0 & 2 & 17.7 & 5.0 & 7.7 & 4.9 & 0.1 & 0.6 & - \\
\hline roducts & 55 & 5 & 2.7 & - & 2.7 & - & - & $<0.1$ & - \\
\hline Goverr & 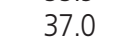 & - & 33.2 & - & 8.5 & 20.4 & 4.3 & 3.7 & - \\
\hline Net C & 173.6 & - & 161.7 & 115.7 & 26.6 & 18.2 & 1.1 & 11.9 & - \\
\hline Government public health activities & 75.4 & - & - & - & - & - & - & - & 75.4 \\
\hline \multicolumn{10}{|c|}{ 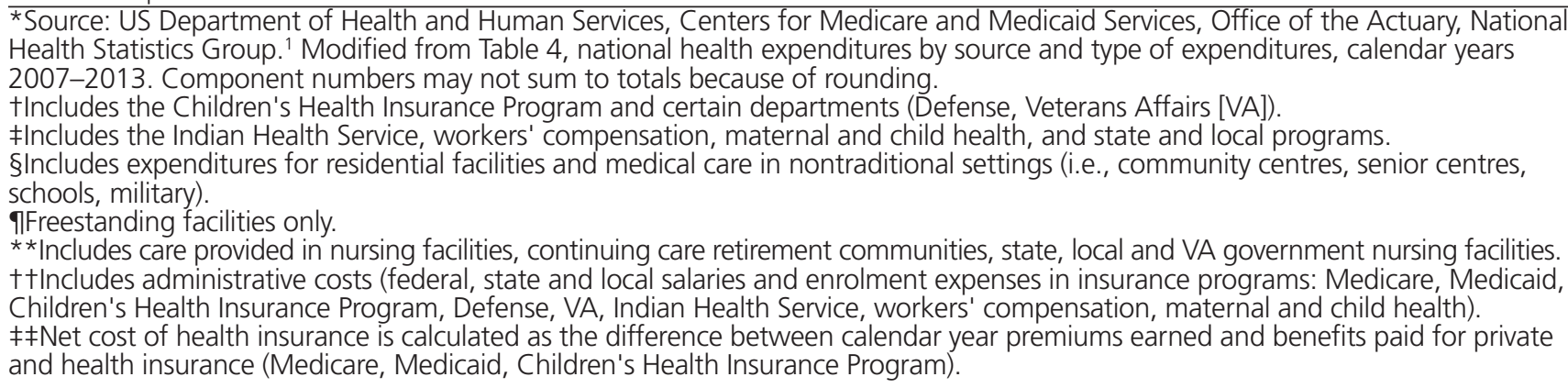 } \\
\hline
\end{tabular}

hospice care, and home health care, with deductibles and limits placed on each type of care. Beneficiaries are also eligible for Medicare Part B coverage, which, for a relatively small health insurance premium, allows senior citizens to obtain extended coverage for physician services, outpatient hospital services, home health care services, and a limited number of outpatient drugs (e.g., hepatitis B vaccine, immunosuppressant drugs, pneumococcal and influenza vaccines, and some oral cancer drugs). Medicare Part C (known as Medicare Advantage) is a managed care component that was added in 1997 , whereby private companies can contract with the Centers for Medicare and Medicaid Services to provide both Part A and B services, along with other services (e.g., optional prescription drug benefit) in either a health maintenance organization (HMO) or a preferred provider organization (PPO) plan. Currently, Part C plans constitute a relatively small part of the Medicare marketplace.

The Medicare Part D (prescription drug) benefit, which is part of the Medicare Prescription Drug, Improvement, and Modernization Act, was initiated on January 1, 2006. ${ }^{3}$ About $45 \%$ of its funding is from federal general tax revenue and the remaining $55 \%$ of funding is from premiums paid by participants in the plans. Enrolment is voluntary. Most prescription drugs and insulin are covered, but some types of prescription drugs are excluded (e.g., for weight loss, erectile dysfunction, and hair growth). Along with the additional premiums paid for Part D coverage, there are also deductibles and copayments, which are based on the category of benefit coverage that the beneficiary is eligible to receive (e.g., standard, low-income, dual-eligible). Some of the problems with the Part D program, such as payment of drugs in the "coverage gap", have been corrected by the ACA. ${ }^{4}$

\section{Medicaid}

Medicaid is a jointly operated federal and state program designed to provide health care for people living in poverty. Medicaid recipients include people who are blind or otherwise disabled, elderly impoverished people, and families with dependent children if one parent is absent, unemployed, or unable to work. Services available to Medicaid recipients 
include inpatient and outpatient hospital care, physician visits, and nursing facility care. Federal funding to states is set on a cost-sharing basis, according to the state's per capita income, whereby wealthier states get less than $50 \%$ and poorer states get more than $50 \%$ of the federal distribution. Although an outpatient prescription program is not mandated by federal regulations, it is an option provided by most states.

Together, Medicare and Medicaid account for nearly threequarters of public expenditures for personal health services (Table 2). ${ }^{2}$ Individual states have turned increasingly toward managed care programs in an attempt to control expenditures. In theory, managed care systems reduce costs by allowing providers to manage treatment of their patients, reducing unnecessary care and focusing on preventive care. In practice, this is not always the case, and despite the growth in managed care plans, most Medicaid dollars are still spent on traditional fee-for-service medicine. Although Medicaid spending is driven by enrolment growth, the vast majority of spending is for older people in nursing facilities and individuals with disabilities.

With the 2010 passage of the ACA, access has improved for most Americans without health insurance. ${ }^{5}$ The Medicaid program is expected to grow substantially, thereby significantly reducing the number of uninsured people, with the federal government picking up most of the cost (about $90 \%$ of the total, with the remaining $10 \%$ paid by states). ${ }^{6}$ Because the ACA is expected to significantly increase enrolment in the Medicaid program, states are concerned about how they are going to pay for their contribution.

\section{Children's Health Insurance Program}

The federal Children's Health Insurance Program was established to ensure that children who do not qualify for Medicaid would be covered by health insurance through to age 18. The program is administered by states, according to federal requirements, and is funded jointly by the states and the federal government. This program is based on the "health care as a right" principle.

\section{Military Medical Care}

The "military medical care system" is a general term referring to the separate systems of the US Army, Navy, and Air Force. This system is responsible for providing health care to active-duty military personnel throughout the world, where care is needed for service-connected problems. As part of the US Department of Health and Human Services (DHHS) Public Health Service, it is an organized federal system where there is no direct cost to the individual for care provided. There is considerable emphasis on injury prevention and health promotion, in addition to sickness care. Medical corpsmen (known as medics) are nonphysician personnel with special training who perform many routine ambulatory care services, referring more complicated cases to physicians. Acute care services are provided at base dispensaries, sick bays aboard ship, or base hospitals at various military installations. Regional military hospitals provide more complex services.

After discharge or retirement, medical care is generally provided at Veterans' Affairs (VA) facilities, which are funded by the federal government. As the nation's largest integrated health care system, the VA operates more than 1400 sites of care, including hospitals, community clinics, and other facilities. Most of the patients are male veterans with multiple systemic problems. Increasingly, women have expanded roles in various military branches, and women's health is a growing area for the VA system.

\section{Indian Health Service}

Treaties signed between American Indian tribes and the US government stipulated that American Indians would receive medical and hospital services, a precedent that continues today. The Indian Health Service is managed by the DHHS Public Health Service, with health care and pharmacy services provided to American Indians and Alaska natives living on or near reservations.

The majority of pharmacists in the Indian Health Service are members of the Commissioned Corps. As Public Health Service officers, these pharmacists were first assigned to hospitals in 1953 to establish dispensing policies and practices. ${ }^{78}$ During the 1960 s, several innovations set the stage for an active clinical pharmacist role. The first innovation was the replacement of the traditional prescription blank with the patient's medical record as the primary document used to fill all prescriptions. By having access to patients' charts, pharmacists can provide concurrent review of prescribed drug therapy for appropriateness before dispensing. The second innovation was that pharmacists in the Indian Health Service were the first to use private counselling rooms and to provide counselling to every patient receiving a prescription. The third major innovation was the provision of primary care to ambulatory patients with both acute and chronic health problems. This program began as pharmacists independently initiated and extended drug therapy. The primary care program has now progressed to the point where pharmacists take histories, do physical assessments, and prescribe treatment, including prescription medications. This unique primary care role of the pharmacist has evolved because of undersupply of physicians in the workforce and the needs of the underserved American Indian population, and is well suited for rural areas. Although the pharmaceutical care role has more recently been advocated in the ambulatory setting, most of these innovations were first developed in the Indian Health Service.

\section{Community Health Centers}

In 1965, Congress funded the Neighborhood Health Center Act to ensure provision of comprehensive health care to 
underserved populations in urban and rural areas of the United States. ${ }^{9}$ In 1973, the Neighborhood Health Center program was transferred to the DHHS Public Health Service, and the freestanding ambulatory care facilities were designated as "Community Health Centers". ${ }^{10}$ In 1974, the Community Health Centers Act required provision of diagnostic treatment and other services by a physician or physician extender, as well as laboratory services, well-child care, dental services, social services, and pharmaceutical services. The 1978 amendments to Sections 329 and 330 of the Public Health Services Act changed the "supplemental" services designation and made pharmacy a "primary" service. All Community Health Centers are now required to provide or arrange for pharmacy services for their patients; some Community Health Centers provide on-site licensed pharmacies, whereas others provide pharmaceuticals through contracted arrangements with an off-site pharmacy. When uninsured Americans need health care, they often rely upon public hospitals, public health clinics, and Community Health Centers.

\section{PRIVATE HEALTH CARE SECTOR}

When most Americans think of the US health care system, they usually think of middle-income families with at least one member having health insurance provided through their employment. In this scenario, ambulatory care services are provided by physicians in private practice or managed care settings. Each individual chooses (or is assigned to) a physician or managed care program to meet his or her own or the family's health care needs. This set of services is paid for directly by the beneficiary or through a private health insurance plan. Either the patient or a primary care physician (e.g., family practice physician) provides coordination within this system. Specialist referral, if needed, is orchestrated by the "gatekeeper" physician. When medications are prescribed, the patient typically decides which community pharmacy will be used.

Although insurance covers most benefits, the policies range from high-deductible plans (e.g., US\$1300 deductible for single coverage with a maximum for out-of-pocket expenses [such as deductible, copayments, coinsurance] of US\$6550) with lower premiums, to standard plans where most of the premium is paid by the employer (with a low deductible of about US $\$ 750$ that is out-of-pocket to the employee). ${ }^{11}$ The beneficiary generally pays out-of-pocket for most of these services until a certain deductible is met and then the health insurance plan takes over the majority of further payments. In the past, most plans covered only hospital and physician expenses. Today, the ACA also requires prescription coverage and preventive services. In addition, the majority of hospital care is covered under most health insurance plans (except for copayments).

\section{Managed Care}

Managed care is the use of a planned and coordinated approach to providing health care, the goal being the provision of health care at the lowest possible cost, including emphasis on preventive care. Managed care is usually offered through a network of providers (HMOs or PPOs) formed to offer costeffective services. An HMO is a prepaid health plan. With HMOs, payment for services is usually prepaid to the provider on a per-member, per-month basis. Thus, the provider is paid the same amount of money every month for a member, regardless of whether that member receives services and regardless of the cost of services (i.e., a service contract). A PPO is an insurance plan in which the managed care organization contracts with providers to provide health services under a discounted fee schedule. This type of plan is also prepaid, with the member or family being enrolled for (usually) a 1-year period and thereby being entitled to certain agreed-upon services. Health care services available through PPOs usually include hospital services, physician visits, prescription drugs, mental health services, and home health care services. Any of these services that are obtained outside the plan are usually not fully reimbursed or may not be reimbursable at all. Thus, financial incentives are built in to encourage members to stay within the system.

The distinctive feature of the private health care system is that patients have the ability to choose their physicians and pharmacists. If satisfied, they maintain these relationships. Managed care also addresses the major limitations of the traditional fee-for-service system, the emphasis on overutilization of resources by the provider and the lack of incentive to encourage healthy lifestyles. With managed care, these incentives are reversed. ${ }^{12}$

\section{Long-Term Care}

If long-term care is needed, a continuum of services is available, some of which are covered by health insurance plans (excluding long-term health insurance) that provide little or no coverage for nursing home costs, such that the individual or family must personally cover costs (or obtain Medicaid coverage). Long-term care is financed by both the private health care sector (e.g., self-paid, long-term insurance plans) and the public health care sector (e.g., Medicare, Medicaid). Increasingly, nursing home plans are being promoted by private insurance companies. Much of long-term care has shifted away from hospital and nursing home settings to home health care groups and hospice settings. A continuum of living arrangements has been developed, ranging from retirement communities with independent living through increasing levels of personal services (e.g., assisted living facilities) to health services in nursing homes and hospitals. 


\section{HEALTH STATUS INDICATORS}

The public health care sector also encompasses various agencies at the federal level, including the DHHS. The Centers for Disease Control and Prevention (CDC) is the DHHS agency responsible for the control and prevention of infectious and some chronic diseases. The CDC provides valuable information through its Healthy People 2020 project $^{13}$ and many other programs focused on improving health.

\section{Life Expectancy}

Life expectancy from birth rose to 78.8 years in 2014 (81.2 years for females and 76.4 years for males). Life expectancy at birth for the white population is 79.0 years, 3.4 years longer than that for the African American population. ${ }^{14}$ Health disparity factors (including access to health care and quality of care) and lifestyle factors account for much of this difference.

\section{Leading Causes of Death}

In 2013, the 10 leading causes of death, in descending order, were heart disease, cancer, chronic lower respiratory tract diseases, unintentional or accidental injuries, stroke, Alzheimer disease, diabetes mellitus, influenza and pneumonia, renal disease, and intentional self-harm (suicide). Infectious (communicable) diseases accounted for 5 of the 10 leading killers in 1900 but only 2 in 2013, and their places have been taken by chronic diseases. ${ }^{15,16}$ For today's top killers, lack of physical activity, poor nutrition, obesity, alcohol abuse, and tobacco use all represent major risk factors.

\section{Crude Death Rate and Infant Mortality Rate}

Between 1900 and 2013, the overall (crude) death rate declined by $50 \%$, and the infant mortality rate declined by $90 \%$, to a record low of 6.0 deaths of infants under 1 year of age per 1000 live births. However, there were sizable differences based on ethnic background, with African Americans and American Indians having much higher infant mortality rates than the white population. ${ }^{17}$ These health disparities suggest that prenatal and postnatal care, especially for nonwhite infants, should be improved. Furthermore, the US infant mortality rate ranking is only 38 th best in the world, a dreadful standing, given that the country spends more on health care (per capita) than any other country. ${ }^{18}$ Many of the leading causes of death are preventable, and given the escalating costs of health care, an economic imperative is to renew interest in disease prevention and health care reform.

\section{PHARMACY WORKFORCE}

\section{Where Pharmacists Practise}

In the United States, the total number of pharmacists is about $291000 .{ }^{19}$ Of this number, about $60 \%$ work in commu- nity pharmacies, including independents, chains, grocery stores, and mass merchants. The second largest group (30\%) consists of pharmacists working in institutional settings, such as hospitals, long-term care facilities, and organized heath systems. The remaining $10 \%$ work in academia, government, and the pharmaceutical industry.

\section{Educational Requirements for Pharmacists}

Since 2000, practising pharmacists have been required to have a Doctor of Pharmacy (PharmD) degree, which consists of 2-4 years in a prepharmacy program and 4 years in a pharmacy program. ${ }^{20}$ Pharmacy education combines didactic classroom learning and experiential training, specifically "Introduction to Pharmacy Practice Experience" training in community and hospital pharmacy settings for each of the first 3 years and "Advanced Pharmacy Practice Experience" as fourth-year rotations.

After graduation, a prospective pharmacist must pass 2 examinations to become a registered pharmacist. The primary exam is the NAPLEX exam (North American Pharmacist Licensure Examination), which measures a candidate's knowledge of the practice of pharmacy. The jurisprudence exam is known as the MPJE (Multistate Pharmacy Jurisprudence Examination), which combines federal- and state-specific questions. Most states also administer their own legal exam covering state-specific regulations.

\section{Residencies, Fellowships, and Graduate Studies}

Pharmacy students have a variety of postgraduate training programs available to them. One option is the postgraduate year 1 (PGY1) residency, which is designed to enhance the general competencies of the resident in managing medication use and supporting optimal drug therapy outcomes. These residencies are usually offered in the hospital setting. However, over the past decade, an increasing number of residencies have been offered in other practice settings (e.g., community pharmacies, home care, long-term care, ambulatory care, and managed care facilities). In addition, the number of pharmacy graduates seeking PGY1 residencies has been increasing in recent years.

A second option is the PGY2 residency, which is available to those who have completed a PGY1 residency. Possibilities for PGY2 residencies include ambulatory care, health-system administration, cardiology, critical care, geriatrics, infectious diseases, informatics, internal medicine, managed care systems, pediatrics, pharmacotherapy, and organ transplant. Often, the PGY2 residency is combined with a third option, the fellowship. As such, the pharmacy specialty fellowship is a directed, postgraduate program designed to prepare the participant to become an independent researcher. Each of these options is available and undertaken after the pharmacist is eligible to practise, not before. 
A fourth option is for the pharmacist to undertake a dual-degree option, with the PharmD/MBA offering further training in business and the PharmD/MPH further training in public health. Finally, a student may pursue graduate training in either pharmaceutical sciences (e.g., medicinal chemistry, pharmacology, dosage-form design) or social and administrative sciences (e.g., social behavioural sciences, economics, management, public health).

\section{Scope of Practice for Pharmacists}

The distribution of medications remains a primary pharmacist responsibility, with over $49 \%$ of pharmacists' time in patient care services associated with medication dispensing. ${ }^{21}$ The remaining $51 \%$ is composed of patient care services not associated with medication dispensing (21\%), business or organization management (13\%), education (7\%), research and scholarship (4\%), and other activities (6\%). Relative to other settings, the proportion of time varies with practice setting: community pharmacists often spend about $67 \%$ of their in dispensing activities, and hospital pharmacists (and those in other patient care roles) spend less than $45 \%$ of their time on dispensing. ${ }^{21}$ Pharmacists also serve as a valuable source of medication-related information for patients and health care providers.

The concept of medication therapy management (MTM) arose from Medicare Part D (the outpatient prescription drug program), where a patient who is taking multiple long-term drugs typically has medication costs of US $\$ 2500$ or more per year. Although MTM is still evolving, a number of systems are in place to support pharmacy practice in this area. One of these is a system used by pharmacy benefit managers (PBMs), which employs clinical decision-making programs to alert the pharmacist to patient care opportunities (e.g., interactions, drug allergies) that can be used to help the patient resolve drug therapy problems. Companies supporting MTM (e.g., OutcomesMTM) also use clinical decision programs to identify opportunities for community pharmacists. A major problem is that these companies generally rely on claims data supplied by the partnering insurance company. Similar to some medical homes, where clinical decision-making programs provide chronic disease information to primary care providers, these data are somewhat useful, but they are no substitute for "real-time" information. Increasingly, medical homes are using real-time electronic records (shared between the provider and the pharmacist), which are vital for quality patient care.

Within the concept of patient-centred (pharmaceutical) care, the pharmacist becomes involved in patient care through both MTM and disease state management. Pharmacists' involvement in disease state management programs is highlighted by the Asheville project in North Carolina. In this project, pharmacists developed concrete strategies to manage specific diseases (e.g., diabetes, asthma) and found that active manage- ment reduced costs and improved patients' health. This project's publications have captured the attention of leaders within the profession and at the governmental level. ${ }^{22-25}$ Pharmaceutical care programs have also been implemented in other states (e.g., Iowa, Minnesota, and North Dakota).

The role of the pharmacist has been further expanded through the vision statement of the Joint Commission of Pharmacy Practitioners, which proposed that "Pharmacists will be the health care professionals responsible for providing patient care that ensures optimal medication therapy outcomes."26 US Surgeon General Regina Benjamin wrote a letter supporting the findings of Scott Giberson and granting provider status to pharmacists. ${ }^{27}$ In 2015, a bill was introduced into the US Congress (House of Representatives) to give the pharmacist "provider status" in areas with shortages of health professionals (mainly underserved rural areas). It is an exciting time for pharmacists to become recognized as health care providers, in addition to being known for the products that we dispense. ${ }^{28}$

\section{Pharmacy Technicians and Drug Distribution Systems}

Pharmacy technicians are a vital part of the pharmacy workforce, particularly in drug distribution. The training of technicians varies from state to state, and each state regulates what technicians can and cannot do. Most technicians are trained on the job in the pharmacy setting, but many others are trained in community colleges and vocational schools. Many pharmacy technicians have taken the national Pharmacy Technician Certification Examination. Most technicians are involved in the dispensing process, and their work is checked by a pharmacist. Some hospitals (specifically those with unitdose distribution systems) have implemented technician-checktechnician programs, but most rely upon pharmacists to check technicians' work before the dispensed drugs are sent to the patient care areas for administration. Technicians in hospital settings are involved in both inpatient and outpatient settings and perform much of the distribution process in unit-dose and intravenous systems. In community pharmacy settings, technicians are involved in the distribution of drugs and perform administrative duties (e.g., collecting payment information from patients).

In some settings, technicians have more advanced functions. For instance, in the North Dakota Telepharmacy Program, a pharmacy technician may operate a community pharmacy in a rural or remote location, under the supervision of a pharmacist who is located in a central, geographically distant pharmacy site, through the use of telecommunication equipment. In this program, the supervisory pharmacist, instead of being physically present a few feet from the pharmacy technician, provides the same level of supervision using a telecommunication camera to observe the dispensing process. ${ }^{29-31}$ Although state pharmacy regulations permit this practice in North Dakota, most other states are more restrictive in their 
telepharmacy regulations. In some states, telepharmacy practice is not permitted at all, even though the use of dispensing robotics equipment is permitted for dispensing of prescriptions in rural and remote areas.

Drug distribution systems in hospitals mainly use the unitdose distribution system and intravenous additive systems. Generally, medications are packaged in unit doses (with bar codes) that allow identification to be tracked from the time of dispensing to the time of administration to the patient. These systems have contributed to the reduction of medication error rates in hospitals. Computers, robotics, and pharmacy technicians are used in hospitals to improve productivity and efficiency in the dispensing process. For example, electronic medication administration records automate the paper record. In 2003, the US Food and Drug Administration required medication bar codes to be placed on all dispensing and prescription containers. Physicians now enter prescriptions for hospital inpatients into a computer, and the prescriptions are then sent to the pharmacy. There, the pharmacist fills and checks the prescriptions against the patient's diagnosis, allergies, and interactions. Finally, the nurse scans the bar code on the patient's bracelet and the bar code on the dispensed medication, and the computer matches the drug and dose ordered; an alarm sounds if a mismatch occurs.

\section{e-Prescribing and PBMs}

Electronic prescribing and PBMs play an important role in the transfer and processing of prescriptions. The Health Information Technology for Economic and Clinical Health Act (the HITECH Act), passed in 2009, was intended to stimulate the adoption of electronic health records in hospitals and physician practices in the United States. ${ }^{32}$ Currently, about $90 \%$ of hospitals ${ }^{33}$ and $74 \%$ of physicians ${ }^{34}$ have adopted electronic health records, which have been shown to improve the efficiency, cost, and safety of patient care. Traditionally, most prescriptions were written on paper by a physician and filled by the pharmacist. Today, the adoption rate of e-prescribing (the electronic delivery of prescription orders) is about $70 \%$ for US physicians and $95 \%$ for community pharmacies. ${ }^{35}$

PBMs carve out the prescription benefit from primary health insurance plans and use online adjudication of pharmacy claims to administer the drug benefit plan. Currently, the largest PBMs are Express Scripts, CVS Health (formerly CVS/Caremark), and United Health/OptumRx/Catamaran. These organizations not only administer prescription claims, but also design pharmaceutical benefits such as formularies, plan designs, mail order pharmacies, manufacturer discounts, and clinical management. Pharmacists have expressed concerns about PBMs, specifically problems with pricing structures, reimbursement, and lack of transparency in contract negotiations. These organizations adjudicate prescription claims for most of the US population. ${ }^{36}$

\section{Prescribing Practices}

Prescribing rights for medical doctors (and doctors of osteopathy) are similar throughout the United States. These health care professionals prescribe prescription drugs that are within their scope of practice. Dentists can also prescribe within their scope of practice (i.e., dental conditions). Prescribing rights for physician extenders (i.e., nurse practitioners and physician assistants) are determined by the state in which they practise: some states allow full prescribing privileges (sometimes even for controlled substances), but most states allow only partial prescribing privileges (in the form of collaborative practice agreements) or require that prescribing be done under the supervision of the physician.

Pharmacists have partial prescribing privileges in some states (e.g., California and Oregon). ${ }^{37}$ Most states require that a pharmacist have a signed collaborative practice agreement with a physician group, denoting what the pharmacist can and cannot do. Most prescribing by pharmacists is limited and occurs within 2 areas_-dependent and collaborative prescribing. Dependent prescribing involves the delegation of authority from the physician to the pharmacist and follows a specific, explicit written protocol (or written guidelines) that includes the types of diseases and the involved drug categories. In federal Indian Health Service clinics, some pharmacists are primary care providers, with prescribing privileges for both acute and chronic disease states. Collaborative prescribing requires a collaborative practice agreement or other formal relationship between the pharmacist and a physician (or practice group); the agreement gives the pharmacist explicit legal authority to prescribe certain medications. Collaborative practice agreements are not the same as protocols, because they do not dictate the activities that the pharmacist will perform in managing a patient's drug therapy. ${ }^{38}$

Pharmacist prescribing continues to be a controversial topic. Some pharmacists want this additional responsibility, and others do not. Although most pharmacy professional organizations support this responsibility, the American Medical Association is opposed to pharmacist prescribing.

\section{ACCESS TO PHARMACEUTICAL PRODUCTS}

Most medicines available in the United States can be purchased directly from pharmaceutical companies, but in practice most are purchased from wholesalers (e.g., Cardinal Health, McKesson). The gross margins for community pharmacies have been decreasing over the past few decades, so the impetus for pharmacies is to reduce inventory, increase prescription volume, and thus generate a higher turnover rate. Therefore, an on-demand ordering and supply system is the most common strategy used to improve inventory control. In the hospital setting, purchasing mechanisms (e.g., group purchasing organizations, buying groups) are used. Some community pharmacies use a central fill site for long-term medications, with pharmacists trying to synchronize a patient's 
multiple medications to a single refill date. The prescriptions are filled overnight and delivered the next day to the community pharmacy.

The US drug approval process is generally recognized as the best in the world. Before a drug is marketed, it goes through a rigorous process of clinical (human) trials (phases I to III), to ensure safety and efficacy, before gaining approval for marketing. Once approved, most products also undergo postmarketing surveillance (phase IV studies) to monitor for adverse reactions.

\section{Availability of the WHO Essential Medicines List}

The essential medicines concept is designed to promote the availability, accessibility, affordability, quality, and rational use of medicines to meet public health needs. This concept underlies the World Health Organization (WHO) Essential Medicines List, first published in 1977, which serves as a model for public supply and reimbursement. Today, more than 130 countries have created national lists of essential medicines based on the WHO model list. The WHO updates the list every 2 years, and the 19th edition was published in $2015 .{ }^{39}$ However, this list (also known as an essential drug list, preferred drug list, or formulary) is generally not followed in the United States, except by a few programs (e.g., state Medicaid programs, PBMs, DHHS Public Health Service, Community Health Centers, VA).,9

In the United States, where the major system is private health care, a formulary is a list of prescription medications available to consumers, and a tiered formulary provides financial incentives for patients to select lower-cost drugs. For instance, with a 3-tier formulary, the first tier typically includes generic drugs with the lowest cost-sharing, the second tier includes preferred brand-name drugs with higher cost-sharing, and the third tier includes nonpreferred brand-name drugs with the highest cost-sharing. For drugs that are not on the formulary, patients must pay a larger percentage of the medication's cost. Formularies vary across drug plans and differ in terms of the breadth of drugs covered and the cost of copayments. Most formularies cover at least one drug in each drug class, and encourage generic substitution. ${ }^{40}$

Given that formularies are designed by the private sector, private health plans may achieve some savings, although these savings are typically much lower than those achieved in countries with a single-payer plan (e.g., Britain, Canada). In a recent study, US prices for the world's 20 top-selling drugs were, on average, 3 times higher than in Britain. ${ }^{41}$

Millar and others ${ }^{42}$ assessed consistency between state Medicaid preferred drug lists and the WHO essential drugs list, and found that only 6 of 120 medicines on the essential drugs list appeared on fewer than $50 \%$ of the preferred drug lists. Furthermore, medicines appearing only on the preferred drugs lists were less likely than those on the WHO essential medicines list to have generic versions available and were less likely to be first-line treatments. The authors concluded that application of the essential medicines concept to Medicaid preferred drug lists could reduce costs and allow for more evidence-based care to low-income patients in the United States. ${ }^{42}$

\section{FUTURE DIRECTIONS AND CONCLUSIONS}

This article has provided a brief overview of the US health care system and its historical evolution, the private and public health care systems, and issues that are associated with health care utilization. While the purpose of health care is to promote health, the US system has historically focused on the diagnosis and treatment of disease. Since 2010, primarily because of implementation of the ACA, the focus is now shifting to health prevention and public health. Although access to health has improved, the costs of health care delivery in the United States remain high.

References

1. National health expenditure data. Baltimore (MD): US Department of Health and Human Services, Centers for Medicare and Medicaid Services; [modified 2015 May 5; cited 2015 Oct 28]. Available from: https://www.cms.gov/Research-Statistics-Data-and-Systems/StatisticsTrends-and-Reports/NationalHealthExpendData/

2. NHE fact sheet. Baltimore (MD): US Department of Health and Human Services, Centers for Medicare and Medicaid Services; [cited 2015 Oct 28]. Available from: https://www.cms.gov/researchstatistics-data-and-systems/statistics-trends-and-reports/nationalhealth expenddata/nhe-fact-sheet.html

3. Drug coverage (part D). Baltimore (MD): US Department of Health and Human Services, Centers for Medicare and Medicaid Services; [cited 2015 Oct 27]. Available from: https://www.medicare.gov/ part-d/index.html

4. Drug coverage (part D). Costs in the coverage gap. Baltimore (MD): US Department of Health and Human Services, Centers for Medicare and Medicaid Services; [cited 2015 Oct 27]. Available from: https:// www.medicare.gov/part-d/costs/coverage-gap/part-d-coverage-gap.html

5. Holahan J, Buettgens M, Carroll C, Dorn S. The cost and coverage implications of the ACA Medicaid expansion: national and state-by-state analysis. Washington (DC): Kaiser Family Foundation; 2012 [cited 2015 Oct 27]. Available from: www.urban.org/sites/default/files/alfresco/ publication-pdfs/412707-The-Cost-and-Coverage-Implications-of-theACA-Medicaid-Expansion-National-and-State-by-State-Analysis.PDF

6. Paradise J, Garfield R. What is Medicaid's impact on access to care, health outcomes, and quality of care? Setting the record straight on the evidence. Washington (DC): Kaiser Family Foundation; 2013 [cited 2015 Oct 27]. Available from: http://kff.org/report-section/what-is-medicaids-impacton-access-to-care-health-outcomes-and-quality-of-care-setting-therecord-straight-on-the-evidence-issue-brief/

7. Paavola FG, Dermanoski KR, Pittman RE. Pharmaceutical services in the United States public health service. Am J Health Syst Pharm. 1997;54(7):766-72.

8. Flowers L, Wick J, Figg WD Sr, McClelland RH, Shiber M, Bitton JE, et al. U.S. Public Health Service Commissioned Corps pharmacists: making a difference in advancing the nation's health. J Am Pharm Assoc (2003). 2009;49(3):446-52.

9. Mezey AP, Lawrence RS. Ambulatory care. In: AR Kovner, editor. Jonas's health care delivery in the United States. New York (NY): Springer; 1995. pp. 122-61.

10. Roemer M. Ambulatory health services in America. Rockville (MD): Aspen System Corporation; 1981.

11. High deductible health plans. In: Wikipedia, the free encyclopedia. Wikipedia Foundation Inc; [cited 2015 Oct 27]. Available from: https://www.wikipedia.org/wiki/High-deductible_health_plan

12. Scott DM. Overview of health and health care in the United States. In: Wertheimer AI, Smith MI, editors. Pharmacy and the U.S. health care system. 4th ed. London (UK): Royal Pharmaceutical Press; 2013. pp. 1-20.

13. Healthy people 2020 [website]. Washington (DC): US Department of Health and Human Services, Office of Disease Prevention and 
Health Promotion; [cited 2015 Oct 28]. Available from: www. healthypeople.gov/

14. Health, United States, 2015: with special feature on racial and ethnic health disparities. Hyattsville (MD): US Department of Health and Human Services, Centres for Disease Control and Prevention, National Center for Health Statistics; 2016 [cited 2016 Jul 18]. Available from: www.cdc.gov/nchs/data/hus/hus15.pdf\#015

15. Leading causes of death, 1900-1998. Atlanta (GA): US Department of Health and Human Services, Centers for Disease Control and Prevention, National Office of Vital Statistics; [cited 2015 Oct 28]. Available from: www.cdc.gov/nchs/data/dvs/lead1900_98.pdf

16. Leading causes of death. Atlanta (GA): US Department of Health and Human Services, Centers for Disease Control and Prevention, National Center for Health Statistics; [cited 2015 Oct 28]. Available from: www.cdc.gov/nchs/fastats/leading-causes-of-death.htm

17. Maternal, infant and child health: infant mortality rates, 2012. Washington (DC): US Department of Health and Human Services, Office of Disease Prevention and Health Promotion; [cited 2015 Oct 29]. Available from: www.healthypeople.gov/2020/data-search/Searchthe-Data?nid= 4825

18. Mortality rate, infant (per 1,000 live births). Geneva (Switzerland): The World Bank; [cited 2015 Oct 28]. Available from: http://data. worldbank.org/indicator/SP.DYN.IMRT.IN

19. Occupational employment statistics: pharmacists. Washington (DC): US Department of Labor, Bureau of Labor Statistics; [cited 2015 Oct 28]. Available from: www.bls.gov/oes/current/oes291051.htm

20. Doctor of Pharmacy (Pharm.D.) degree. Alexandria (VA): American Association of Colleges of Pharmacy; [cited 2015 Oct 28]. Available from: www.aacp.org/resources/student/pharmacyforyou/documents/pharmd.pdf

21. Gaither CA, Schommer JC, Doucette WR, Kreling DH, Mott DA. Final report of the 2014 national pharmacist workforce sample survey to determine contemporary demographic practice characteristics and quality of work-life. Minnesota (MN): Midwest Pharmacy Workforce Research Consortium; 2015 [cited 2016 Feb 24]. Available from: www.aacp.org/ resources/research/pharmacyworkforcecenter/Documents/FinalReportOf TheNationalPharmacistWorkforceStudy2014.pdf

22. Bunting BA, Cranor CW. The Asheville project: long-term clinical, humanistic, and economic outcomes of a community-based medication therapy management program for asthma. J Am Pharm Assoc (2003). 2006;46(2):133-47.

23. Cranor CW, Christensen DB. The Asheville Project: short-term outcomes of a community pharmacy diabetes care program. J Am Pharm Assoc (Wash). 2003;43(2):149-59.

24. Cranor CW, Christensen DB. The Asheville project: factors associated with outcomes of a community pharmacy diabetes care program. $J \mathrm{Am}$ Pharm Assoc (Wash). 2003;43(2):160-72.

25. Cranor CW, Bunting BA, Christensen DB. The Asheville project: longterm clinical and economic outcomes of a community pharmacy diabetes care program. J Am Pharm Assoc (Wash). 2003;43(2):173-84.

26. Vision statement. Joint Commission of Pharmacy Practitioners; [cited 2016 Jul 28]. Available from: www.accp.com/docs/positions/misc/ JCPPvisionstatement.pdf

27. Giberson S, Yoder S, Lee MP. Improving patient and health system outcomes through advanced pharmacy practice. A report to the U.S. Surgeon General 2011. Washington (DC): US Public Health Service, Office of the Chief Pharmacist; 2011 [cited 2015 Oct 20]. Available from: www.accp.com/docs/positions/misc/improving_patient_and_health_ system_outcomes.pdf

28. Get the facts: provider status. Washington (DC): American Pharmacists Association; [cited 2015 Oct 20]. Available from: www.pharmacist.com/ get-facts-provider-status

29. Petersen CD, Scott DM, Rathke A, Killingsworth P, Hill G. Establishing a central order entry site for delivering telepharmacy services to remote rural hospitals. J Pharm Technol. 2010;26:179-86.

30. Scott DM, Friesner DL, Rathke AM, Peterson CD, Anderson HC. Differences in medication errors between central and remote site telepharmacies. J Am Pharm Assoc (2003). 2012;52(5):e97-e104.
31. Friesner DL, Scott DM, Rathke AM, Peterson CD, Anderson HA. Do remote community telepharmacies have higher medication error rates than traditional community pharmacies? Evidence from the North Dakota Telepharmacy Project. J Am Pharm Assoc (2003). 2011; 51(5):580-90.

32. Definition: HITECH Act (Health Information Technology for Economic and Clinical Health Act) [website]. TechTarget; [cited 2015 Oct 28]. Available from: http://searchhealthit.techtarget.com/definition/ HITECH-Act

33. Hospital progress to meaningful use: hospital progress to meaningful use by size, type, and urban/rural location. Washington (DC): US Department of Health and Human Services, Office of the National Coordinator for Health Information Technology; 2016 Mar [cited 2015 Oct 28]. Available from: http://dashboard.healthit.gov/quickstats/pages/FIGHospital-Progress-to-Meaningful-Use-by-size-practice-setting-areatype.php

34. Health IT dashboard: Office-based physician health IT adoption. Washington (DC): US Department of Health and Human Services, Office of the National Coordinator for Health Information Technology; [cited 2016 Jul 18]. Available from: http://dashboard.healthit.gov/ dashboards/physician-health-it-adoption.php

35. Gabriel MH, Swain M. E-prescribing trends in the United States. ONC Data Brief No. 18. Washington (DC): US Office of the National Coordinator for Health Information Technology; 2014 [cited 2015 Oct 28]. Available from: https://www.healthit.gov/sites/default/files/ oncdatabriefe-prescribingincreases2014.pdf

36. Pharmacy benefit management. In: Wikipedia, the free encyclopedia. Wikipedia Foundation Inc; [cited 2015 Oct 28]. Available from: https://en.wikipedia.org/wiki/Pharmacy_benefit_management

37. Ostrov BF. Pharmacists can prescribe 'the pill' in these states. CNN News. 2015 Jul 14 [cited 2015 Oct 28 ]. Available from: www.cnn. com/2015/07/14/health/pharmacist-prescribe-hormonal-contraceptives/

38. Task Force on Pharmacist Prescribing. An information paper on pharmacist prescribing within a health care facility. Ottawa $(\mathrm{ON})$ : Canadian Society of Hospital Pharmacists; [cited 2015 Mar 2]. Available from: http://cjhp-online.ca/index.php/cjhp/article/viewFile/545/639

39. Annex 1. 19th WHO model list of essential medicines. Geneva (Switzerland): World Health Organization; 2015 [cited 2015 Oct 28]. Available from: www.who.int/medicines/publications/essential medicines/EML2015_8-May-15.pdf

40. Formulary (pharmacy). In: Wikipedia, the free encyclopedia. Wikipedia Foundation Inc; [cited 2015 Oct 20]. Available from: https://en. wikipedia.org/wiki/Formulary_\%28pharmacy\%29

41. Hirschler B. Exclusive - transatlantic divide: how U.S. pays three times more for drugs. Reuters; 2015 Oct 12 [cited 2016 Jul 17]. Available from: www.reuters.com/article/us-pharmaceuticals-usa-comparisonidUSKCNOS61KU20151012

42. Millar TP, Wong S, Odierna DH, Bero LA. Applying the essential medicines concept to US preferred drug lists. Am J Public Health. 2011;101(8):1444-8.

David M Scott, MPH, PhD, is a Professor with the School of Pharmacy, North Dakota State University College of Health Professions, Fargo, North Dakota.

Competing interests: None declared.

\section{Address correspondence to:}

Dr David M Scott

School of Pharmacy

North Dakota State University College of Health Professions

118k Sudro

Fargo ND 58108-6050 USA

e-mail: david.scott@ndsu.edu 